\title{
Effects of low-intensity pulsed ultrasound (LIPUS) applied on the temporomandibular joint (TMJ) region on the functional treatment of class II malocclusion: A randomized controlled trial
}

\section{Oddziaływania ultradźwięków o niskiej intensywności stosowanych na okolicę stawu skroniowo-żuchwowego w leczeniu czynnościowym wad zgryzu klasy II - randomizowane badanie kontrolowane}

\author{
Mohammad Osama Namera ${ }^{A-F}$, Ghiath Mahmoud ${ }^{\mathrm{A}, \mathrm{D}-\mathrm{F}}$, Abdulaziz Abdulhadi ${ }^{\mathrm{A}-\mathrm{F}}$, Ahmad Burhan ${ }^{\mathrm{A},-\mathrm{F}}$ \\ Department of Orthodontics, Faculty of Dentistry, University of Damascus, Syria \\ A - research concept and design; B - collection and/or assembly of data; C - data analysis and interpretation; \\ $D$ - writing the article; $E$ - critical revision of the article; $F$ - final approval of the article
}

Address for correspondence

Mohammad Osama Namera

E-mail: osamanamera@gmail.com

Funding sources

None declared

Conflict of interest

None declared

Received on June 28, 2019

Reviewed on September 3, 2019

Accepted on September 13, 2019

Published online on March 31, 2020

Cite as

Namera MO, Mahmoud G, Abdulhadi A, Burhan A. Effects of low-intensity pulsed ultrasound (LIPUS) applied on the temporomandibular joint (TMJ) region on the functional treatment of class II malocclusion: A randomized controlled trial. Dent Med Probl. 2020;57(1):53-60. doi:10.17219/dmp/112321

DOI

$10.17219 / \mathrm{dmp} / 112321$

Copyright

○) 2020 by Wroclaw Medical University

This is an article distributed under the terms of the

Creative Commons Attribution 3.0 Unported License (CC BY 3.0)

(https://creativecommons.org/licenses/by/3.0/)

\begin{abstract}
Background. Low-intensity pulsed ultrasound (LIPUS) is considered one of the techniques used to improve the mandibular growth. Many animal studies have reported that significant results can be obtained using LIPUS therapy with functional appliances.

Objectives. This research aimed to evaluate the dentoskeletal changes produced by the combination of LIPUS therapy and functional treatment during the correction of skeletal class II malocclusion.

Material and methods. Forty-five patients aged 10.5-14 years with skeletal class II division 1 malocclusion were randomly divided into 3 equal groups: the LIPUS group, treated with a Twin-Block appliance in combination with LIPUS therapy; the TB group, treated with a Twin-Block appliance only; and the control group, which was observational and received no treatment. Cephalometric changes were compared between the 3 groups using the analysis of variance (ANOVA) and Tukey's post hoc tests at $p<0.05$.

Results. A greater significant decrease in the ANB (A point, nasion, B point) angle was observed in the treated groups $\left(-2.67^{\circ}\right.$ for the LIPUS group and $-2.11^{\circ}$ for the TB group) as compared to the control group $(p<0.001)$. A greater improvement in the mandibular length and position was observed in the LIPUS group than in the TB group $(p<0.001)$. The changes in the control group as a result of continuing growth were minimal and clinically non-significant.

Conclusions. The application of LPUS therapy in combination with functional treatment can have a great effect on growth stimulation during the correction of class II malocclusion. In addition, LIPUS was effective in reducing the duration of functional treatment.
\end{abstract}

Key words: Twin-Block appliance, low-intensity pulsed ultrasound (LIPUS), functional orthodontic treatment

Słowa kluczowe: aparat Twin-Block, ultradźwięki o niskiej intensywności (LPUS), ortodontyczne leczenie czynnościowe 


\section{Introduction}

Class II malocclusion is one of the most frequent orthodontic problems, as its occurrence ranges from $18 \%$ to approx. $32 \%$ of the population, ${ }^{1}$ and most class II malocclusion cases are the result of mandibular deficiency and not of maxillary excess. ${ }^{2,3}$ The treatment of class II malocclusion varies widely; growth modification treatment shows the best results in patients with growth potential, but it depends on the phase of skeletal growth. ${ }^{4,5}$

A wide range of functional appliances have been used to stimulate the mandibular growth by forwarding the mandible; they can cause a significant improvement in the facial esthetics and occlusal relationships. ${ }^{6}$ Several techniques have been suggested to improve the mandibular growth, such as low-level laser therapy (LLLT), growth hormones and low-intensity pulsed ultrasound (LIPUS). Moreover, these techniques can also reduce the duration of functional treatment. ${ }^{7}$

Recently, LIPUS has been applied to accelerate bone fracture healing. ${ }^{8,9}$ In addition, it can stimulate the mandibular growth by effectively increasing the cartilaginous growth potential in the mandibular condylar cartilage. The U.S. Food and Drug Administration (FDA) has tested and approved the following parameters: a $1.5-\mathrm{MHz}$ sine wave, repeated at $1 \mathrm{kHz}$ at an intensity of $30 \mathrm{mw} / \mathrm{cm}^{2}$, with a pulse width of $200 \mu \mathrm{s}$, delivered for $20 \mathrm{~min}$ a day.

Many animal studies have reported that significant results can be obtained using LIPUS therapy combined with functional appliances. ${ }^{10,11}$ El-Bialy et al. evaluated the effectiveness of LIPUS therapy with functional appliances in treating patients with hemifacial microsomia (HFM) ${ }^{12}$ They concluded that a daily application of LIPUS with hybrid bite-jumping appliances had significantly improved growth in the affected side of the patients' mandible. ${ }^{12}$ Maurya et al. also studied the effects of LIPUS therapy with fixed functional appliances. ${ }^{13}$ They concluded that LIPUS therapy positively affects the size of the joint space, improving the outcomes of functional treatment in growing patients with skeletal class II malocclusion. ${ }^{13}$

The purpose of this randomized controlled clinical trial (RCT) was to evaluate the changes resulting from the combined treatment with LIPUS and functional appliances (Twin-Block) in the correction of skeletal class II malocclusion.

\section{Material and methods}

\section{Trial design}

This study was designed as a three-pronged RCT with 1:1:1 allocation ratio. It was conducted at the Department of Orthodontics, Faculty of Dentistry of the University of Damascus in Syria, between March 2017 and November 2018. This trial was registered at the Clinical Trials.gov website on August 16, 2017 (identifier: NCT03251807). The local Research Ethics Committee approval was obtained. No serious harm to the patients was noticed.

\section{Sample size calculation}

The G*Power software, v. 3.1.3 (the Heinrich Heine University, Düsseldorf, Germany), available at http://www.psychologie.hhu.de/fileadmin/redaktion/ Fakultaeten/Mathematisch-Naturwissenschaftliche_Fakultaet/Psychologie/AAP/gpower/GPowerWin_3.1.9.7.zip, was used to determine the sample size. A statistical power of $95 \%$ and $\alpha$-error of $5 \%$ were assumed. The mean differences in the ANB angular measurements in the 3 groups were used based on the results of Baysal and Uysal, ${ }^{14}$ and the one-way analysis of variance (ANOVA) test was applied. This indicated a sample size of 14 patients in each group. This study involved 15 patients in each group to compensate for the potential dropouts.

\section{Eligibility criteria for participants, setting and location of data collection}

The participants in the trial were selected randomly from the patients who arrived for consultation at the Department of Orthodontics, according to the following eligibility criteria: skeletal class II division 1 malocclusion with normal maxilla and retrognathic mandible $\left(\mathrm{SNB}<78^{\circ}\right)$, with the ANB values from $4^{\circ}$ to $8^{\circ}$, and an overjet of 6-10 $\mathrm{mm}$; patients at the pubertal growth spurt peak, which was assessed using hand-wrist radiographs according to the Fishman method of skeletal maturation. ${ }^{15}$

The exclusion criteria were the following: previous orthodontic treatment; systemic diseases that may affect the orthodontic treatment results; severe facial asymmetry; and poor oral hygiene.

The parents of the patients who met the inclusion criteria and were invited to participate were informed about the study; then, informed consent for each patient was obtained.

\section{Randomization}

The 45 enrolled patients were listed and a computergenerated randomization was applied to divide the patients into 3 equal groups. The distribution was concealed from the patient and the researcher until the time of intervention.

\section{Blinding}

Blinding of the patient or of the operator during intervention was not applied throughout the trial.

However, blinding during assessment was performed. The pre- and post-treatment cephalograms were saved and coded by an assistant (not involved in the study), so the researcher was unaware which group each radiograph belonged to when the records were evaluated. 


\section{Interventions}

Forty-five patients aged 10.5-14 years were involved in the trial and randomly divided into 3 equal groups ( 2 treated and 1 control). The $1^{\text {st }}$ group was the LIPUS group, receiving the combined treatment with LIPUS and a functional Twin-Block appliance. The $2^{\text {nd }}$ group was the TB group; it received functional treatment with TwinBlock only. The $3^{\text {rd }}$ group was an observational group (the control group), receiving no intervention.

Each patient in both treated groups had a single-step mandibular advancement and an edge-to-edge incisal relationship with a 2-3-mm bite opening between the central incisors. Twin-Block appliances with the conventional design according to Clark $^{16}$ consisted of 2 plates with a midline screw in the maxillary plate, which was turned once per week $(0.2 \mathrm{~mm})$ by the patient.

In the LIPUS group, gel was applied on the right and left temporomandibular joint (TMJ) regions to ensure LIPUS wave propagation, and the UltraCure PRO Plus ${ }^{\mathrm{TM}}$ device (EZUltrasound, Mobridge, USA) was used. The device generated $200-\mu$ s bursts of a $1-\mathrm{MHz}$ sine wave with a repetition rate of $1 \mathrm{kHz}$ and a temporal averaged intensity of $30 \mathrm{mw} / \mathrm{cm}^{2}$. These parameters have been approved by FDA. ${ }^{17}$

The LIPUS stimulation was applied for 20 min daily for the first 21 days of the treatment and every 3 weeks during the active phase of functional treatment (Fig. 1). This treatment protocol has been used in a variety of human and animal models to stimulate bone fracture healing by inducing new vascularization as well as to promote growth and healing after distraction ostogenesis. ${ }^{18,19}$ In addition, El-Bialy et al. in 2010 applied a similar LIPUS treatment protocol in their study on patients with HFM. ${ }^{12}$

All participants in the treated groups were instructed to wear their appliances at all times except at meal time, and were checked every 3 weeks until the end of the active phase of the functional therapy. The active phase was ended when the overjet was $0-1.5 \mathrm{~mm}$ and the occlusion settled into a class I or superclass I molar relationship. ${ }^{14}$ The control group was monitored for 8 months.
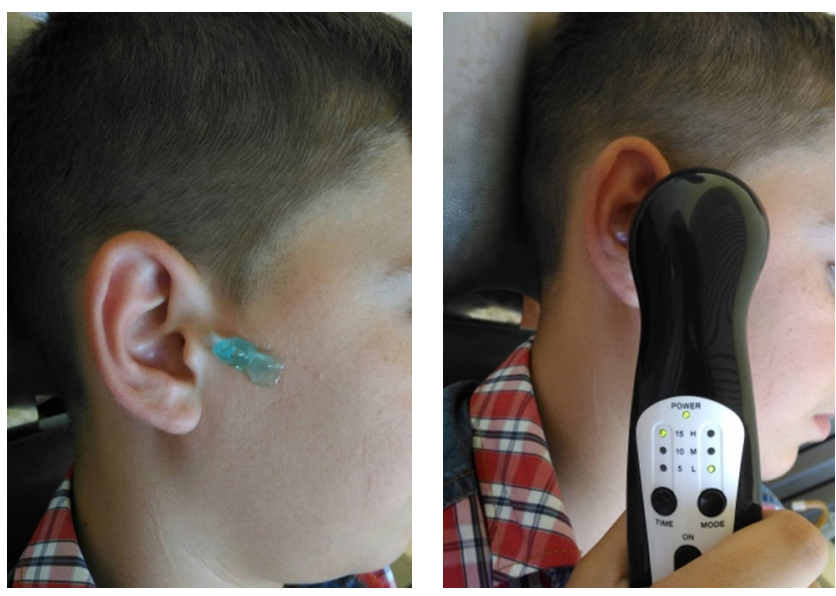

Fig. 1. Technique of applying the low-intensity pulsed ultrasound (LIPUS) device on the temporomandibular joint (TMJ) region

\section{Cephalometric analysis}

Lateral cephalometric radiographs were obtained before and at the end of the active phase of the treatment for the treated groups, and at the beginning and end of the observation period for the control group. All cephalometric radiographs were taken with the same machine, i.e., PaX-i3D (VATEH Co., Ltd., Hwaseong, Korea), with the same settings. The cephalograms were traced and analyzed using cephalometric software (Viewbox, v. 4.0.1.6; dHAL Software, Kifissia, Greece) by the same researcher, who was blinded to the patients' names during the measurement.

\section{Outcomes}

The skeletal and dentoalveolar changes after the treatment or observation were evaluated by measuring 11 angular variables and 5 linear variables (measured in millimeters) on the lateral cephalometric radiographs (Fig. 2). Ten randomly selected cephalograms were retraced and analyzed after 1 month to determine the method error. Reliability was evaluated using the intraclass correlation coefficient (ICC), which revealed a strong intra-examiner reliability $(\mathrm{ICC}=0.992)$. The paired-sample $t$-test was applied to all cephalometric measurements to detect any systematic error. No statistically significant difference was found between the 2 measurements $(p>0.05)$.

\section{Statistical analysis}

The data was gathered and analyzed using the IBM SPSS Statistics for Windows, v. 20.0 software (IBM Corp., Armonk, USA). The $\chi^{2}$ tests were used to assess differences in gender distribution between the groups. The Shapiro-Wilk normality test was used to ensure the normal distribution of data. The paired sample $t$-test was used to study the significance of differences between the pre- and post-treatment variables in each group, and to detect the intra-group changes after the treatment/observation; the level of significance was set at $p<0.05$.

The one-way analysis of variance (ANOVA) and Tukey's multiple comparison post hoc test were used to assess the significance of differences between the 3 groups after the treatment/observation, and the level of significance was set at $p<0.05$.

\section{Results}

\section{Pre-treatment equivalence}

Forty-five patients were randomized with a 1:1:1 allocation ratio into 3 groups (15 patients in each group). No patients were lost during the follow-up and a total of 45 patients were available for the statistical analysis (Fig. 3). There was no significant difference between the groups 

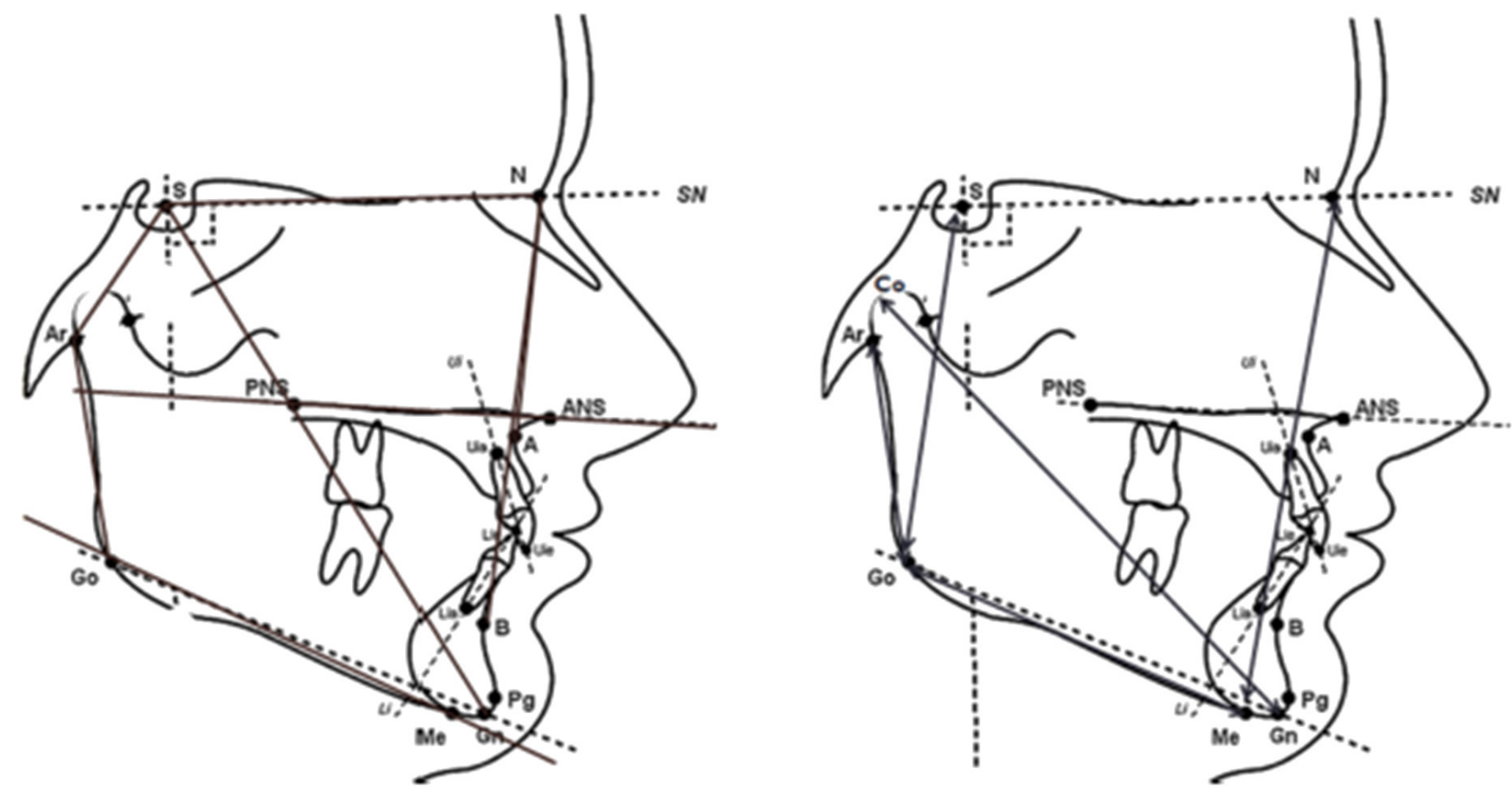

Fig. 2. Cephalometric measurements on the radiograms

A - A point; ANS - anterior nasal spine; Ar - articular; B - B point; Gn - gnathion; Go - gonion; Me - menton; N - nasion; Pg - pogonion; PNS - posterior nasal spine; S - sella.

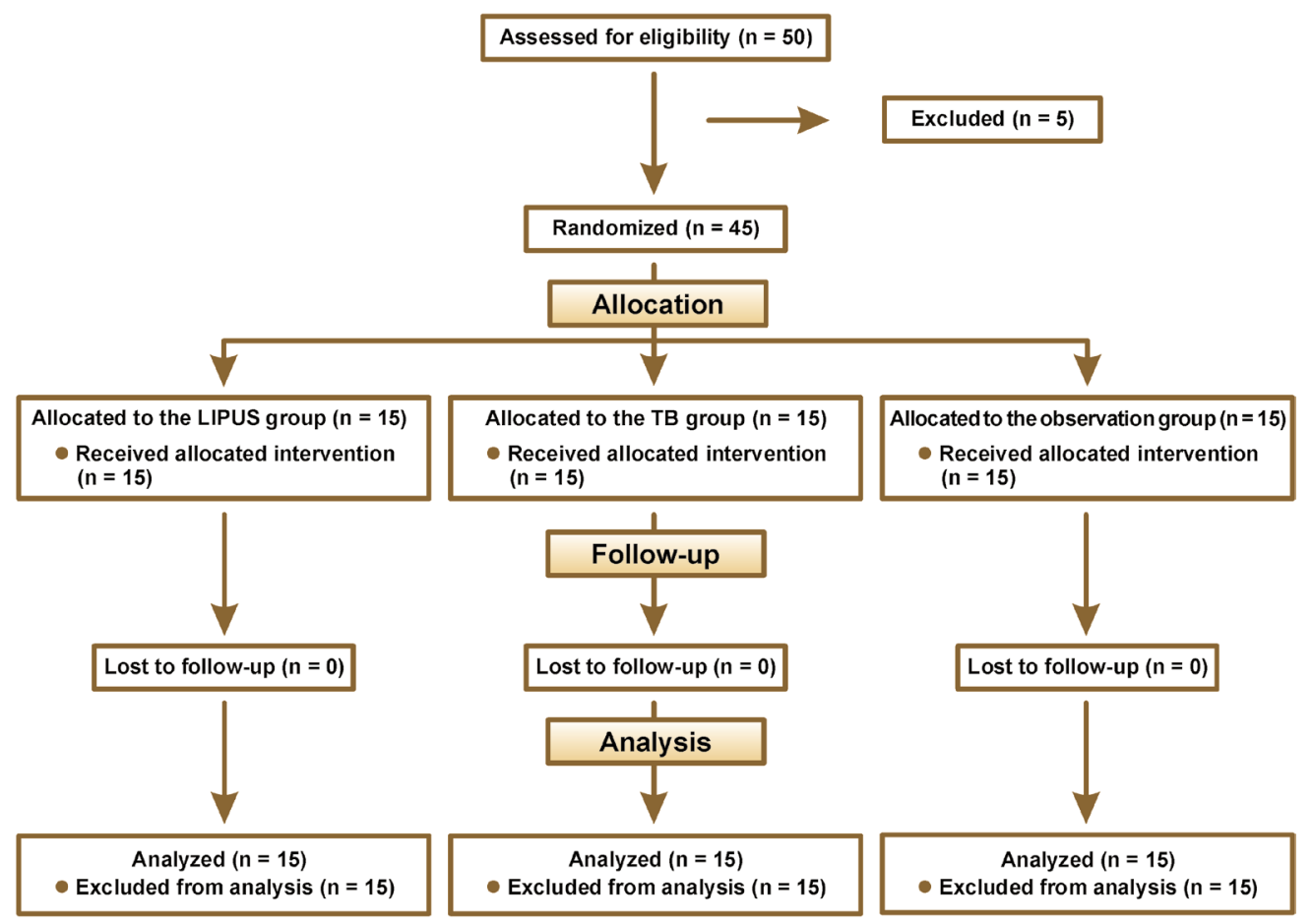

Fig. 3. CONSORT (Consolidated Standards of Reporting Trials) flow diagram of the patients' recruitment and follow-up

LIPUS - low-intensity pulsed ultrasound; TB - Twin-Block.

regarding gender distribution at the start of the study (the $\chi^{2}$ tests with Yates's correction: $X^{2}=0.556 ; p=0.757$ ) (Table 1). The ANOVA test indicated no statistically significant differences between the 3 groups for all the studied variables before the treatment $(p>0.05)$, with the exception of the $\mathrm{Y}$-axis and the inclination of the maxillary incisors to the maxilla plane, the former being significantly larger in the control group than in the LIPUS and TB groups (Table 2).

\section{Intra-group comparison}

The changes after the treatment or observation period in each group are presented in Table 3. 
Table 1. Gender distribution between the groups

\begin{tabular}{|c|c|c|c|c|c|c|}
\hline Sex & LIPUS group & TB group & Control group & Total & $x^{2}$ & $p$-value \\
\hline Males (n) & 5 & 6 & 8 & 19 & \multirow{3}{*}{0.556} & \multirow{3}{*}{0.757} \\
\hline Females (n) & 10 & 9 & 7 & 26 & & \\
\hline Total (N) & 15 & 15 & 15 & 45 & & \\
\hline
\end{tabular}

Table 2. Comparison of pre-treatment cephalometric variables

\begin{tabular}{|c|c|c|c|c|c|c|c|c|c|c|c|}
\hline \multirow{2}{*}{\multicolumn{2}{|c|}{ Variables }} & \multicolumn{2}{|c|}{ LIPUS group } & \multicolumn{2}{|c|}{ TB group } & \multicolumn{2}{|c|}{ Control group } & \multirow{2}{*}{$p$-value } & \multicolumn{3}{|c|}{ Multiple comparison } \\
\hline & & mean & $S D$ & mean & $S D$ & mean & $S D$ & & LIPUS/TB & LIPUS/control & TB/control \\
\hline \multirow{11}{*}{ 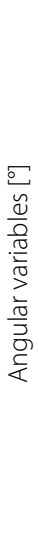 } & SNA & 81.40 & 2.23 & 81.78 & 1.98 & 80.92 & 2.66 & 0.924 & NS & NS & NS \\
\hline & SNB & 74.98 & 2.08 & 74.97 & 1.52 & 75.01 & 2.02 & 0.644 & NS & NS & NS \\
\hline & ANB & 6.47 & 0.69 & 6.81 & 0.96 & 5.93 & 0.85 & 0.074 & NS & NS & NS \\
\hline & NSAr & 125.42 & 5.85 & 123.86 & 5.80 & 126.00 & 3.98 & 0.395 & NS & NS & NS \\
\hline & SArGo & 140.88 & 4.30 & 143.13 & 3.30 & 142.05 & 3.70 & 0.620 & NS & NS & NS \\
\hline & ArGoMe & 130.40 & 7.37 & 125.74 & 4.61 & 128.39 & 6.72 & 0.166 & NS & NS & NS \\
\hline & Total sum of Björk & 396.70 & 5.05 & 395.97 & 3.53 & 398.55 & 5.22 & 0.627 & NS & NS & NS \\
\hline & Y-axis & 60.49 & 3.18 & 61.06 & 2.82 & 62.47 & 2.18 & 0.008 & NS & 0.009 & 0.040 \\
\hline & MM & 30.09 & 4.73 & 30.72 & 3.02 & 32.58 & 4.09 & 0.621 & NS & NS & NS \\
\hline & U1:Spp & 111.87 & 4.41 & 111.32 & 4.98 & 114.26 & 1.80 & 0.020 & NS & NS & 0.020 \\
\hline & L1:GoMe & 98.56 & 5.45 & 97.71 & 8.05 & 95.69 & 7.69 & 0.736 & NS & NS & NS \\
\hline \multirow{5}{*}{ 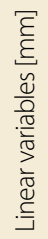 } & Ramus height (Ar-Go) & 48.10 & 6.42 & 50.42 & 5.48 & 50.73 & 5.38 & 0.763 & NS & NS & NS \\
\hline & Mandibular body (Go-Me) & 85.69 & 8.50 & 82.33 & 5.98 & 79.86 & 6.70 & 0.776 & NS & NS & NS \\
\hline & Mandibular length (Co-Gn) & 135.25 & 8.23 & 134.77 & 6.88 & 134.65 & 5.87 & 0.938 & NS & NS & NS \\
\hline & Wits & 5.58 & 1.98 & 6.50 & 1.38 & 5.98 & 2.20 & 0.789 & NS & NS & NS \\
\hline & Overjet & 7.23 & 0.96 & 7.33 & 1.57 & 7.60 & 1.57 & 0.395 & NS & NS & NS \\
\hline
\end{tabular}

SD - standard deviation; MM - intermaxillary angle; U1 - upper central incisor; Spp - palatal plane; L1 - lower central incisor; Co - condylion; NS - non-significant.

Table 3. Comparison of the changes in the angular and linear variables between the 3 groups

\begin{tabular}{|c|c|c|c|c|c|c|c|c|c|c|c|c|c|}
\hline \multirow{2}{*}{\multicolumn{2}{|c|}{ Variables }} & \multicolumn{3}{|c|}{ LIPUS group } & \multicolumn{3}{|c|}{ TB group } & \multicolumn{3}{|c|}{ Control group } & \multicolumn{3}{|c|}{ Multiple comparison } \\
\hline & & mean & $S D$ & $p$-value & mean & $S D$ & $p$-value & mean & $S D$ & $p$-value & LIPUS/TB & LIPUS/control & TB/control \\
\hline \multirow{11}{*}{ 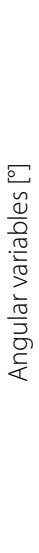 } & SNA & 0.47 & 0.48 & 0.002 & 0.42 & 0.26 & $<0.001$ & 0.12 & 0.09 & NS & NS & 0.004 & 0.021 \\
\hline & SNB & 3.23 & 0.77 & $<0.001$ & 3.09 & 0.61 & $<0.001$ & 0.30 & 0.10 & $<0.001$ & NS & $<0.001$ & $<0.001$ \\
\hline & ANB & -2.69 & 0.72 & $<0.001$ & -2.67 & 0.66 & $<0.001$ & -0.21 & 0.17 & $<0.001$ & NS & $<0.001$ & $<0.001$ \\
\hline & NSAr & -1.96 & 0.58 & $<0.001$ & -1.66 & 0.88 & $<0.001$ & 0.33 & 0.16 & 0.035 & NS & $<0.001$ & 0.012 \\
\hline & SArGo & 2.05 & 0.87 & $<0.001$ & 1.91 & 1.00 & $<0.001$ & -0.20 & 0.47 & NS & NS & $<0.001$ & $<0.001$ \\
\hline & ArGoMe & 1.18 & 1.28 & NS & 0.81 & 1.04 & 0.022 & -0.15 & 0.46 & 0.037 & 0.021 & NS & $<0.001$ \\
\hline & Total sum of Björk & 1.27 & 1.99 & 0.014 & -0.22 & 1.00 & NS & 0.02 & 0.09 & NS & 0.009 & 0.027 & NS \\
\hline & Y-axis & 0.01 & 0.88 & NS & -0.29 & 0.79 & NS & 0.43 & 0.32 & NS & NS & NS & NS \\
\hline & MM & 0.53 & 1.60 & 0.044 & 0.21 & 0.54 & NS & 0.39 & 0.38 & NS & 0.010 & 0.020 & NS \\
\hline & U1:Spp & -2.60 & 1.68 & $<0.001$ & -3.22 & 0.95 & $<0.001$ & -0.27 & 0.22 & $<0.001$ & 0.001 & $<0.001$ & $<0.001$ \\
\hline & L1:GoMe & 2.74 & 1.23 & 0.033 & 3.30 & 1.19 & $<0.001$ & 0.25 & 0.35 & NS & NS & $<0.001$ & $<0.001$ \\
\hline \multirow{5}{*}{ 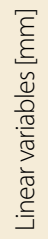 } & Ramus height (Ar-Go) & 2.37 & 1.19 & $<0.001$ & 2.25 & 0.85 & $<0.001$ & 0.84 & 0.28 & 0.020 & 0.021 & $<0.001$ & $<0.001$ \\
\hline & Mandibular body (Go-Me) & 1.55 & 1.62 & $<0.001$ & 2.21 & 0.77 & $<0.001$ & 1.03 & 0.45 & NS & NS & 0.0130 & $<0.001$ \\
\hline & Mandibular length (Co-Gn) & 4.09 & 1.21 & 0.001 & 3.54 & 0.79 & $<0.001$ & 0.77 & 0.23 & NS & 0.002 & $<0.001$ & $<0.001$ \\
\hline & Wits & -4.83 & 1.21 & $<0.001$ & -5.43 & 1.22 & $<0.001$ & 0.07 & 0.19 & NS & NS & $<0.001$ & $<0.001$ \\
\hline & Overjet & -5.94 & 0.74 & $<0.001$ & -5.27 & 1.33 & $<0.001$ & -0.06 & 0.40 & 0.001 & NS & $<0.001$ & $<0.001$ \\
\hline
\end{tabular}




\section{Treated groups (LIPUS and TB)}

Similar, statistically significant changes were observed in the LIPUS and TB groups after the treatment.

There was a significant decrease in the value of ANB $(p<0.001)$, which was caused by a significant increase in SNB and the anterior displacement of TMJ, which was demonstrated by a significant decrease in NSAr $(p<0.001)$. Also, there was a significant increase in the mandibular length (Co-Gn; $4.09 \mathrm{~mm}$ for the LIPUS group and $3.54 \mathrm{~mm}$ for the TB group), whereas SNA showed a minimal increase in both groups.

There were minimal increases in the vertical skeletal relationships, as the vertical angles (total sum of Björk and MM) were increased in the LIPUS group, whereas no statistically significant changes were observed in the TB group.

As for the dentoalveolar changes, the lower incisors were significantly proclined $(p<0.001)$. Also, the upper incisors were significantly retruded $\left(-2.60^{\circ}\right.$ in the LIPUS group and $-3.22^{\circ}$ in the TB group). The overjets were significantly decreased $(p<0.001)$.

\section{Control group}

There were minimal changes in the sagittal angular variables $\left(0.30^{\circ}\right.$ for $\mathrm{SNB}$ and $-0.21^{\circ}$ for ANB). The posterior displacement of TMJ was observed through an increase in NSAr $(p=0.035)$. Changes in the vertical measurements and all linear measurements were not statistically significant, except the Ar-Go measurement, which showed a significant increase $(p=0.020)$. The lower incisor angles were not changed, whereas the upper incisors were minimally retruded $\left(-0.27^{\circ}\right)$ and the overjets were statistically significantly reduced $(-0.06 \mathrm{~mm})(p<0.001)$.

\section{Inter-group comparison}

Multiple comparisons between the groups after the treatment or observation period are presented in Table 3.

Both treated groups showed a greater statistically significant increase in SNA, SNB and ANB as compared to the control group $(p<0.05)$, without any significant difference between the treated groups. A similar, statistically significant decrease was observed in NSAr $(p<0.001)$ in each treated group, whereas NSAr was significantly increased in the control group. Greater increases in the ramus height (Ar-Go) and mandibular length (Co-Gn) were observed in the LIPUS group as compared to the TB group $(p=0.021$ and $p=0.002$, respectively), and in both treated groups in comparison with the control group $(p<0.001)$. Changes in the mandibular body showed a greater significant increase in the treated groups as compared to the control group.

There were minimal increases in the vertical angles (total sum of Björk and MM) in the LIPUS group only.
The differences in the Y-axis were not significant between the 3 groups. Upper incisor retroclination was significant in the TB group as compared to the LIPUS group and the control group $(p<0.001)$, whereas the lower incisors were more protruded in the treated groups than in the control group. Also, the overjets were significantly more decreased in the treated groups compared to the control group $(p<0.001)$, without any significant difference between the treated groups.

\section{Discussion}

Low-intensity pulsed ultrasound is one of the noninvasive approaches that is used to enhance bone growth and formation during functional treatment. This RCT was the first study to evaluate the effects of LIPUS combined with functional appliances on the stimulation of the mandibular growth in patients with class II malocclusion. The LIPUS device produces mechanical waves at a pulse frequency of $1 \mathrm{MHz}$ with a pulse repetition frequency of $1 \mathrm{kHz}$. Daily treatment with LIPUS for $20 \mathrm{~min}$ at an intensity of $30 \mathrm{mw} / \mathrm{cm}^{2}$ (according to FDA) has been found to stimulate bone healing. A daily direct application of LIPUS for 21 days has also been found to stimulate the mandibular bone growth in rats and in humans, especially when combined with functional appliances. ${ }^{12,13}$

In the current study, all patients were at the peak of the pubertal growth spurt to ensure the best effects of the treatment. The cephalometric changes were evaluated at the end of the active phase of functional treatment.

\section{Sagittal skeletal changes}

In both treated groups, SNA was minimally increased, but this increase was not clinically significant. It might be due to the fact that the upper incisor apex was forwarded in both groups and point A moved anteriorly as the result of alveolar bone reshaping; the sagittal growth of the maxilla did not occur. In their study, O'Brien et al. reported the restriction of the maxillary growth, ${ }^{20}$ whereas other researchers did not. ${ }^{21}$ In the control group, no significant changes were observed in SNA $(p=0.452)$.

A greater mandibular length increase in a shorter time was observed in the LIPUS group as compared to the TB group and the control group $(p<0.001)$. After $166 \pm 18.9$ days of active functional treatment, an increase in the mandibular length (Co-Gn) was $4.09 \mathrm{~mm}$ in the LIPUS group, whereas it was $3.54 \mathrm{~mm}$ after $245 \pm 27.2$ days in the TB group. The independent samples $t$-test showed a significant difference between the 2 groups $(p=0.002)$, which means that LIPUS significantly shortened the duration of active functional treatment. This result agrees with the study by El-Bialy et al. on the affected mandibles. ${ }^{12}$

The treated groups showed a significant increase in $\mathrm{SNB}$ as the result of point $\mathrm{B}$ moving to a more anterior 
position ( $3.23^{\circ}$ in the LIPUS group and $3.09^{\circ}$ in the TB group), whereas the changes in the control group were not clinically significant. This was reported in several studies, ${ }^{14,22}$ although the LIPUS group in the current study has shown a greater increase than in the case of Tümer and Gültan's study after 12-16 months of active functional treatment. ${ }^{23}$

The anterior movement of TMJ was obvious from a significant decrease in NSAr in both treated groups, and there was no significant difference between the treated groups. Although many previous studies have reported the anterior movement of TMJ as a significant finding after functional treatment, ${ }^{24}$ many studies have neglected this variable. ${ }^{14,25}$

In both treated groups, ANB was decreased. This decrease had an effect on the skeletal discrepancy between the jaws. This result agreed with previous studies, which demonstrated the great role of functional appliances in improving the relationship between the maxilla and the mandible. ${ }^{5,26}$

\section{Vertical skeletal changes}

Minimal, statistically significant increases in the vertical measurements (total sum of Björk and MM) were observed in the LIPUS group only, which may possibly be related to the effects of the application of LIPUS. However, the TB group showed no significant changes in the vertical measurements. It appears that the posterior acrylic bite blocks of the Twin-Block appliance might be able to prevent any increases in the vertical dimension. Burhan and Nawaya reported a similar result. ${ }^{22}$ In contrast, this result disagrees with the results provided by Giuntini et al. - the posterior acrylic bite blocks of the Twin-Block appliance in the latter study were trimmed only in patients with a deep bite. ${ }^{27}$

Conversely, the treated groups showed a statistically significantly greater elongation of the ramus height $(p<0.001)$ as compared to the control group. This result closely resembles that of Mills and McCulloch's study, where a 2.9- mm increase in the ramus height was reported..$^{21}$

\section{Dental changes}

The dentoalveolar components demonstrated a significant inclination of the anterior teeth in both treated groups, whereas the dentoalveolar changes in the control group were not clinically significant. The upper incisors were also more retruded in the TB group $\left(-3.22^{\circ}\right)$ than in the LIPUS group $\left(-2.60^{\circ}\right)$. This result proved that the correction of class II malocclusion depending on dentoalveolar changes was greater in the LIPUS group than in the TB group.

Many studies have mentioned a significant lower incisor proclination during functional treatment. ${ }^{22,27}$ The retrusion of the upper incisors is also a consistent finding in many previous studies. ${ }^{21,28}$
These dentoalveolar changes significantly contributed to the correction of the overjet. The overjet showed a greater correction in both treated groups as compared to the control group. These results represent a desirable consequence of the treatment of skeletal class II malocclusion, and were achieved by the combination of dentoalveolar and skeletal changes which occurred in the treated groups. ${ }^{22,29}$

\section{Conclusions}

Based on the results of the current study, it can be concluded that the combined treatment with LIPUS and functional appliances is of great effectiveness in correcting class II malocclusion in growing individuals. It accelerates the growth of the mandible and improves the skeletal discrepancy. Therefore, LIPUS could shorten the duration of functional treatment.

A limitation of this study is a lack of cone-beam computed tomography (CBCT) imaging, which can help in measuring the TMJ component dimensions and mandibular dimensions more accurately. However, it is not ethical to order CBCT to patients in an observation group, as no treatment is given to them.

\section{ORCID iDs}

Mohammad Osama Namera (D) https://orcid.org/0000-0002-0118-7140 Ghiath Mahmoud (D) https://orcid.org/0000-0002-1808-8472 Abdulaziz Abdulhadi (D) https://orcid.org/0000-0002-2883-5670 Ahmad Burhan (D) https://orcid.org/0000-0002-0727-2653

\section{References}

1. Bishara SE, ed. Textbook of Orthodontics. Philadelphia, PA: W.B. Saunders Company; 2001.

2. Rosenblum RE. Class II malocclusion: Mandibular retrusion or maxillary protrusion? Angle Orthod. 1995;65(1):49-62.

3. Basciftci FA, Uysal T, Büyükerkmen A, Sari Z. The effects of activator treatment on the craniofacial structures of Class II division 1 patients. Eur J Orthod. 2003;25 (1):87-93.

4. Jena AK, Duggal R. Treatment effects of twin-block and mandibular protraction appliance-IV in the correction of class II malocclusion. Angle Orthod. 2010;80(3):485-491.

5. Cozza P, Baccetti T, Franchi L, De Toffol L, McNamara JA Jr. Mandibular changes produced by functional appliances in Class II malocclusion: A systematic review. Am J Orthod Dentofacial Orthop. 2006;129(5):599.e1-e12.

6. Proffit WR, White RP Jr. Who needs surgical-orthodontic treatment? Int J Adult Orthodon Orthognath Surg. 1990;5(2):81-89.

7. Oksayan R, Ciftci ME, Aktan A, Sokucu O. Biostimulation of mandibular condyle growth. J Orthod Res. 2015;3(3):147-150.

8. Yang KH, Parvizi J, Wang SJ, et al. Exposure to low-intensity ultrasound increases aggrecan gene expression in a rat femur fracture model. J Orthop Res. 1996;14(5):802-809.

9. Mayr E, Frankel V, Rüter A. Ultrasound - an alternative healing method for nonunions? Arch Orthop Trauma Surg. 2000;120(1-2):1-8.

10. El-Bialy T, El-Shamy I, Graber TM. Growth modification of the rabbit mandible using therapeutic ultrasound: Is it possible to enhance functional appliance results? Angle Orthod. 2003;73(6):631-639.

11. El-Bialy T, Hassan A, Albaghdadi T, Fouad HA, Maimani AR. Growth modification of the mandible with ultrasound in baboons: A preliminary report. Am J Orthod Dentofacial Orthop. 2006;130(4):435.e7-e14.

12. El-Bialy T, Hasan A, Janadas A, Albaghdadi T. Nonsurgical treatment of hemifacial microsomia by therapeutic ultrasound and hybrid functional appliance. Open Access J Clin Trials. 2010;2:29-36. 
13. Maurya RK, Jayan B, Singh H, Nakra O, Sharma P. Effects of lowintensity pulsed ultrasound therapy on the temporomandibular joint complex in conjunction with a fixed functional appliance: A prospective 3-dimensional cone beam computed tomographic study. J Ultrasound Med. 2019;38(7):1661-1676.

14. Baysal A, Uysal T. Dentoskeletal effects of Twin Block and Herbst appliances in patients with Class II division 1 mandibular retrognathy. Eur J Orthod. 2014;36(2):164-172.

15. Fishman LS. Radiographic evaluation of skeletal maturation: A clinically oriented method based on hand-wrist films. Angle Orthod. 1982;52(2):88-112.

16. Clark WJ. Twin Block Functional Therapy: Applications in Dentofacial Orthopaedics. $2^{\text {nd }}$ ed. London, UK: Mosby: 2002.

17. Tajali SB, Houghton P, MacDermid JC, Grewal R. Effects of low-intensity pulsed ultrasound therapy on fracture healing: A systematic review and meta-analysis. Am J Phys Med Rehabil. 2012;91(4):349-367.

18. Shimazaki A, Inui K, Azuma Y, Nishimura N, Yamano Y. Low-intensity pulsed ultrasound accelerates bone maturation in distraction osteogenesis in rabbits. J Bone Joint Surg Br. 2000;82(7):1077-1082.

19. Kristiansen TK, Ryaby JP, McCabe J, Frey JJ, Roe LR. Accelerated healing of distal radial fractures with the use of specific, low-intensity ultrasound: A multicenter, prospective, randomized, double-blind, placebo-controlled study. J Bone Joint Surg Am. 1997;79(7):961-973.

20. O'Brien K, Wright J, Conboy F, et al. Effectiveness of early orthodontic treatment with the Twin-block appliance: A multicenter, randomized, controlled trial. Part 1: Dental and skeletal effects. Am J Orthod Dentofacial Orthop. 2003;124(3):234-243,quiz 339.

21. Mills CM, McCulloch KJ. Treatment effects of the twin block appliance: A cephalometric study. Am J Orthod Dentofacial Orthop. 1998;114(1):15-24.

22. Burhan AS, Nawaya FR. Dentoskeletal effects of the Bite-Jumping Appliance and the Twin-Block Appliance in the treatment of skeletal Class II malocclusion: A randomized controlled trial. Eur J Orthod. 2015;37(3):330-337.

23. Tümer N, Gültan AS. Comparison of the effects of monoblock and twin-block appliances on the skeletal and dentoalveolar structures. Am J Orthod Dentofacial Orthop. 1999;116(4):460-468.

24. Baccetti T, Franchi L, McNamara JA Jr, Tollaro I. Early dentofacial features of Class II malocclusion: A longitudinal study from the deciduous through the mixed dentition. Am J Orthod Dentofacial Orthop. 1997:111(5):502-509.

25. Parkin NA, McKeown HF, Sandler PJ. Comparison of 2 modifications of the twin-block appliance in matched Class II samples. Am J Orthod Dentofacial Orthop. 2001;119(6):572-577.

26. Schaefer AT, McNamara JA Jr, Franchi L, Baccetti T. A cephalometric comparison of treatment with the Twin-block and stainless steel crown Herbst appliances followed by fixed appliance therapy. Am J Orthod Dentofacial Orthop. 2004;126(1):7-15.

27. Giuntini V, Vangelisti A, Masucci C, Defraia E, McNamara JA Jr, Franchi L. Treatment effects produced by the Twin-block appliance vs the Forsus Fatigue Resistant Device in growing Class II patients. Angle Orthod. 2015;85(5):784-789.

28. Lund DI, Sandler PJ. The effects of Twin Blocks: A prospective controlled study. Am J Orthod Dentofacial Orthop. 1998;113(1):104-110.

29. Baccetti T, Franchi L, Toth LR, McNamara JA Jr. Treatment timing for Twin-block therapy. Am J Orthod Dentofacial Orthop. 2000;118(2):159-170. 